\title{
The Fate of the Pregnant Diabetic in a Developing Country: Kenya
}

\author{
R. B. Fraser \\ Department of Obstetrics and Gynaecology, University of Nairobi, Kenya
}

\begin{abstract}
Summary. A six-year survey of pregnancies complicated by diabetes has been performed at the Kenyatta National Hospital, Nairobi. Fifty-five babies were delivered with 14 perinatal deaths - a perinatal mortality rate of $254 / 1000$, which was five times that of the nondiabetic population. There was one maternal death. Diabetes tended to be of short duration compared with similar series reported from developed countries. There were no perinatal deaths within a small sub-group managed according to a simple plan based on early referral for antenatal care, monitoring of diabetic control by blood glucose, and timing of delivery by use of the 'shake test'.
\end{abstract}

Key words: Pregnancy, diabetes, developing country, perinatal mortality.

Diabetes mellitus is a relatively rare disease in SubSaharan Africa and few doctors in that area have experience of treating the pregnant diabetic. One small series of cases has been reported from Nigeria [1] and a larger series from South Africa [2]. The low frequency of diabetes in Africans is almost certainly accounted for by dietary rather than racial factors [3], although ascertainment rates may be low. There is little doubt, however, that the frequency of detected diabetes is increasing in African populations [2].

In Kenya, as in many other countries, a woman who is a reproductive failure is often also a social failure and where facilities exist to keep diabetics alive, it seems only fair to enable them to produce healthy babies. Sutton [4] working in the Fiji Islands has shown that fetal suvival can be improved dramatically by the careful application of simple techniques. This paper reports preliminary results which suggest that similar improvements can be made in Africa.

\section{Patients and Methods}

The Kenyatta National Hospital, Nairobi, is a large hospital providing general medical services for the city and specialist referral services for the whole country, and is a teaching hospital for undergraduates. The present study includes all diabetic patients referred to the hospital who achieved 28 weeks gestation in the 6-year period July 1973 to June 1979 . They have been divided into three groups, on the bases of duration of pregnancy when first seen and nature of management.

Series 1: Patients first seen by an obstetrician after 32 weeks gestation, or in labour (16 patients); Series 2: Patients first seen by an obstetrician before 32 weeks gestation (27 patients); Series 3: A group of patients seen for the first time before 32 weeks gestation, who were closely supervised in an attempt to maintain fasting blood glucose levels below $5.5 \mathrm{mmol} / 1$. Elective delivery was delayed until the 'shake test' proved positive (nine patients).

The patients were classified by the criteria of White [5] (Table 1); complications of diabetes are given as footnotes. The treatment prescribed during pregnancy is shown in Table 2. The diagnosis of diabetes was accepted in patients who were under treatment before pregnancy. Diabetes was diagnosed in pregnancy by a $50 \mathrm{~g}$ oral glucose tolerance test using the criteria of the WHO Expert Committee [6], i.e. a 2-h capillary blood glucose exceeding $7.7 \mathrm{mmol} / \mathrm{l}$.

Except in the obese, the diabetic clinic policy was not to restrict diet other than the simple restriction of refined carbohydrates. Patients well controlled on chlorpropamide were continued on this during pregnancy. Single daily injections of lente insulin were commonly used in the non-pregnant. During pregnancy a regimen of twice or thrice daily injections of bovine soluble insulin was usually adopted.

In Series 1 and 2 blood glucose control varied in accordance with the ideas of the clinician concerned. In Series 3 blood glucose profiles were obtained once or twice weekly, the profiles consisting of the fasting level and the levels $3 \mathrm{~h}$ after breakfast and $3 \mathrm{~h}$ after the midday meal. Additional levels were obtained when control proved difficult. Analysis of blood glucose was performed by a glucose oxidase technique or the Dextrostix/Eyetone system (Ames).

\section{Obstetric Management}

The Series 3 patients were admitted for assessment following the first visit. Subsequently they were seen at one or two weekly intervals when weight, blood pressure, urinalysis and abdominal exami- 
Table 1. Distribution of White's classes and perinatal losses

\begin{tabular}{lcclc}
\hline White class & Series 1 & Series 2 & Series 3 & Total \\
\hline A & $2(1)^{\mathrm{a}}$ & $2(1)$ & - & $4(2)$ \\
B & $13(7)^{\mathrm{b}}$ & $18(3)$ & 4 & $35(10)$ \\
C & 1 & 5 & $5^{\mathrm{c}}$ & 11 \\
D & - & $1(1)^{\mathrm{d}}$ & - & $1(1)$ \\
F + R & - & $1(1)^{\mathrm{e}}$ & - & $1(1)$ \\
\hline
\end{tabular}

${ }^{\mathrm{a}}$ Perinatal losses in paratheses $;{ }^{\mathrm{b}}$ Group contains one patient with peripheral neuropathy; ${ }^{\circ}$ Group contains one patient with typical foot ulcer; ${ }^{\mathrm{d}}$ One patient who had had bilateral cataract extractions; ${ }^{\mathrm{c}}$ One patient with diabetic nephropathy

nation were performed. At 32 weeks' gestation they were admitted. In-patients had daily urinalyses and blood pressure readings, were weighed weekly and had a weekly measurement of uterine size. Polyhydramnios was diagnosed if two experienced obstetricians considered the liquor volume to be excessive.

Pre-eclampsia was diagnosed when the blood pressure rose to $140 / 90 \mathrm{mmHg}$, having been normal at an earlier stage in pregnancy. The patients in Series 3 had abdominal radiography at 36 weeks' gestation to exclude bony fetal abnormalities.

The 'shake test' is a bubble stability test performed on liquor amnii as a side-ward procedure [7]. It correlates well with the lecithin/sphingomyelin area ratio [8] and is therefore a useful indicator of functional maturity of the fetal lung. A 'shake test' was performed weekly from 37 weeks' gestation until it was unequivocally positive. Elective delivery was then arranged.

\section{Delivery and Perinatal Care}

In the presence of unfavourable obstetric features delivery was by elective Caesarean section under general anaesthesia. In the other cases induction of labour by forewater amniotomy and oxytocin infusion was attempted. Patients remaining undelivered $12 \mathrm{~h}$ after amniotomy were delivered by Caesarean section. During labour insulin was given to the Series 3 patients at 2 -h intervals by the IM route attempting to keep the blood glucose in the range 4-7 mmol $/ 1$. The usual requirement was $2-3 \mathrm{U} / \mathrm{h}$. Puerperal insulin requirements were calculated according to serial blood glucose measurements.

Paediatricians attended all births and the infants were observed in the newborn nursery for the first few days of life. Early feeding was routine. Some doctors elected to give IV dextrose in addition. All mothers breast-fed; the pre-term infants were fed breast milk by oro-gastric tube. Gestational age was estimated by the Dubowitz scoring system which includes physical and neurological criteria [9]. Weight for gestational age was assessed on the centile charts of Thompson et al. [10]. Respiratory distress was diagnosed clinically. Mild hyperbilirubinaemia was treated by phototherapy. Severe hyperbilirubinaemia was diagnosed when the serum indirect bilirubin exceeded $340 \mathrm{mmol}$.

\section{Results}

Fifty-one patients were followed through 52 pregnancies resulting in 55 infants after 28 weeks' completed gestation. Their mean parity was $3.5 \pm 2.5 \mathrm{SD}$ and the overall perinatal mortality before the diagnosis of diabetes was $128 / 1000$. The means $\pm \mathrm{SD}$ and ranges of ages of the mothers at confinement were: Series 1:29 \pm 5.7 years $(20-37)$; Series $2: 29 \pm 6.2$ years $(17-40)$;
Series 3: $25 \pm 4.7$ years $(19-34)$; overall $28 \pm 5.9$ years $(17-40)$. Perinatal losses in relation to the severity of the diabetes are shown in Table 1.

Amongst the 40 patients diagnosed before the onset of pregnancy the mean duration of the disease was $3.4 \pm 2.9$ years. The only two patients who had had diabetes for more than 10 years were in Series 3 . Twelve patients were diagnosed for the first time during the pregnancy studied, eight of whom proved to have gestational diabetes by the WHO criteria [6]. Three patients had non-pregnant weights greater than $84 \mathrm{~kg}$.

The mean gestational maturity when first seen in the obstetric unit was: Series 1:35weeks; Series 2: 26 weeks; Series 3: 25 weeks; overall: 29 weeks. Three patients were seen for the first time in labour. The methods employed to treat the diabetes are given in Table 2. The mean blood glucose values are compared with perinatal mortality in Table 3 . Ten patients required emergency treatment for hypoglycaemia on one or more occasions, eight of them in Series 2. The only patient who required treatment for ketoacidosis was also in Series 2.

\section{Obstetric Complications}

Two patients had pre-existing hypertension which deteriorated in late pregnancy. Two patients developed mild pre-eclampsia (blood pressure $>140 /$ $90 \mathrm{mmHg}$ ). Polyhydramnios was diagnosed in $16 \mathrm{pa}-$ tients $(30 \%)$ evenly distributed between the three series. Pyelonephritis occurred in one patient.

Labour began spontaneously before 37 weeks of gestation in nine $(17 \%)$ of patients, one of whom had a twin pregnancy. Forty patients were delivered after 37 weeks' gestation. The overall Caesarean section rate was $31 \%$, of which half were elective.

\section{Maternal Complications}

One patient, a well controlled Class $\mathrm{C}$ diabetic in Series 3 , had an anaesthetic-related death following emergency Caesarean section.

A poorly controlled Class B diabetic in Series 1 suffered a ruptured uterus when shoulder dystocia complicated the delivery of a stillborn infant.

\section{Fetal and Neonatal Complications}

The 55 infants included three sets of twins. There were eight stillbirths, 47 livebirths, and six deaths in the first week of life. These figures are analysed in Table 4.

There was also one late death in a Series 1 baby which developed septicaemia from cross-infection in 
Table 2. Treatment of maternal diabetes in pregnancy and perinatal losses

\begin{tabular}{|c|c|c|c|c|c|}
\hline & $\begin{array}{l}\text { No. of infants } \\
\text { delivered }\end{array}$ & Diet alone & $\begin{array}{l}\text { Chlorpropamide } \\
\text { alone }\end{array}$ & $\begin{array}{l}\text { Chlorpropamide later } \\
\text { changed to insulin }\end{array}$ & Insulin alone \\
\hline Series 1 & 17 & $4(2)$ & $5(3)$ & $2(1)$ & $6(2)$ \\
\hline Series 2 & 28 & $3(1)$ & 4 & $4(1)$ & $17(4)$ \\
\hline Series 3 & 10 & - & - & 2 & 8 \\
\hline Total & 55 & $7(3)$ & $9(3)$ & $8(2)$ & $31(6)$ \\
\hline
\end{tabular}

Perinatal losses in parentheses

Table 3. Perinatal losses related to maternal mean pre-prandial blood glucose levels in late pregnancy ${ }^{\mathrm{a}}$

\begin{tabular}{llllll}
\hline $\begin{array}{l}\text { Mean pre-prandial } \\
\text { blood glucose }\end{array}$ & Series 1 & Series 2 & Series 3 & Total & Perinatal mortality \\
\hline$>8.3 \mathrm{mmol} / 1$ & 3 & 9 & 2 & 14 & $6(43 \%)$ \\
$5.5-8.3 \mathrm{mmol} / 1$ & 1 & 6 & 5 & 12 & 0 \\
$<5.5 \mathrm{mmol} / 1$ & 0 & 2 & 3 & 5 & 0 \\
\hline
\end{tabular}

a Patients who had not had profiles performed in each of the last 2 weeks of pregnancy are excluded from this analysis

the nursery. The fresh stillbirth in Series 2 was a baby with hydrocephalus. No other congenital abnormalities were detected, but none of the dead babies was subjected to post-mortem examination. Poor diabetic control was an aetiological factor in six of the eight stillbirths. Pre-term birth was an aetiological factor in four of the six first week deaths. The neonatal complications in the three series are analysed in Table 5.

Amongst 13 babies who had positive 'shake tests' before elective delivery, two had mild respiratory distress, responding within $24 \mathrm{~h}$ to incubator care with supplementary oxygen.

\section{Discussion}

Diabetes mellitus is an emerging disease in Africa, and as Campbell [3] has demonstrated in black South Africans the background incidence of $0.1 \%$ persists amongst rural dwellers, but amongst urbanised Africans, who consume much more 'refined' carbohydrate in their diets the frequency is $3.9 \%$. Our patients are a mixture of urban and rural dwellers, the former providing about seven cases per annum. The perinatal mortality of the non-diabetic urban obstetric population is estimated to be around $50 / 1000$, the main reasons being premature labour $(50 \%)$, ante-partum haemorrhage (12\%), labour related deaths $(12 \%)$ and unexplained intrauterine death $(9 \%)$.

In Notelovitz's South African series [2], where all potential diabetics were screened by a glucose loading technique, 75 of 94 patients ( $80 \%$ ) were diagnosed in pregnancy. In our series only $12(23 \%)$ were diagnosed in the index pregnancy, suggesting that many such cases are perhaps being missed. If so, this might represent a major factor in the unexplained intra-uterine deaths recorded in our perinatal mortality figures.
Table 4. Outcome of pregnancy in diabetic patients

\begin{tabular}{lcclc}
\hline & Series 1 & Series 2 & Series 3 & Total \\
\hline Livebirths & 11 & 26 & 10 & 47 \\
$\begin{array}{l}\text { Stillbirths } \\
\quad \text { macerated }\end{array}$ & 5 & 1 & - & 6 \\
$\quad 1$ resh & 1 & 1 & - & 2 \\
$\begin{array}{l}\text { Deaths in first } \\
\quad 2\end{array}$ & 4 & - & 6 \\
$\begin{array}{l}\text { week } \\
\text { PNM } / 1000\end{array}$ & 470 & 214 & 0 & $254^{\mathrm{b}}$ \\
$\quad$ births & & & & \\
\hline
\end{tabular}

a PNM: Perinatal mortality is

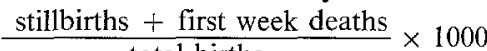
total births

${ }^{b}$ Combined PNM excluding Series 3 patients $=311 / 1000$

Table 5. Neonatal complications

\begin{tabular}{lllll}
\hline & $\begin{array}{l}\text { Series 1 } \\
(n=17)\end{array}$ & $\begin{array}{l}\text { Series2 } \\
(n=28)\end{array}$ & $\begin{array}{l}\text { Series3 } \\
(n=10)\end{array}$ & $\begin{array}{l}\text { Total } \\
(n=55)\end{array}$ \\
\hline $\begin{array}{l}\text { Asphyxia (APGAR } \\
\text { score < 6 at 1 min) }\end{array}$ & 1 & 3 & - & 4 \\
$\begin{array}{l}\text { Shoulder dystocia } \\
\begin{array}{l}\text { Neonatal } \\
\text { hypoglycaemia }\end{array}\end{array}$ & 1 & 2 & - & 3 \\
$\begin{array}{l}\text { (blood glucose } \\
<1.5 \text { mmol/1) }\end{array}$ & & 11 & - & 16 \\
$\begin{array}{l}\text { Neonatal hyperbili- } \\
\text { rubinaemia }\end{array}$ & & & & \\
$\quad \begin{array}{l}\text { mild } \\
\text { severe }\end{array}$ & 2 & & & \\
Respiratory distress & 2 & - & - & 2 \\
$\quad$ mild & 1 & - & 3 & 4 \\
$\quad$ severe & 1 & 2 & - & 3 \\
\hline
\end{tabular}

Thirty-nine of our patients $(75 \%)$ were in White's Class A or B compared with 184/483 (38\%) in a large European series [11], a distribution which may explain the low frequency of long-term diabetic complications in our series. 
Early referral to the ante-natal clinic improves the prognosis. Many authorities comment on the wisdom of close co-operation between a physician and an obstetrician in the management of pregnant diabetics. In the African peripheral hospital the obstetrician may find himself desperately short of comforting colleagues, and we endeavour to teach the routine control of blood glucose levels to our postgraduates. Skilled help may be required in the management of ketoacidosis but fortunately this is a rare complication. We are not opposed to the use of oral hypoglycaemic drugs in pregnancy and others have used them in African patients with good results [2].

Good control of blood glucose is the main problem and we agree with Stowers and Sutherland [12] that in our small series of patients on chlorpropamide, as in theirs, the rather high perinatal mortality (three out of nine) is related to maternal hyperglycaemia rather any specific effect of the drug. Insulin remains the mainstay of treatment, and given twice or thrice daily in a short-acting form will be the drug of choice for most of our patients.

The majority of our patients were delivered electively or spontaneously after 37 weeks' gestation. This accords with the usual practice. With the high perinatal mortality and in the absence of intra-partum fetal monitoring, we do not consider a Caesarean section rate of $31 \%$ to be excessive. There is a higher than expected incidence of respiratory distress in babies of diabetic mothers [13], but in most series the problem seems to be transient tachypnoea of the newborn [14], a condition which is relatively benign when basic facilities for neonatal care are available. The use of the 'shake test' or the lecithin: sphingomyelin area ratio in timing delivery is more controversial, and doubt has been cast on its value in pregnant diabetics [15, 16]. In this series two of 13 babies with positive 'shake tests' had mild respiratory distress, but survived without obyious sequelae. We agree with Sutton [4] that the 'shake test' is of considerable value in predicting newborn survival in the peripheral hospital where its main advantage is its ready availability. A simplified technique has recently been described [17].

The avoidance of neonatal hypoglycaemia in Series 3 babies is consoling, especially as newborn care may be less than optimal.

In conclusion, it has been shown that the combination of poor diabetic care and poor ante-natal care in a 'high risk' obstetric population can produce a perinatal mortality rate between 30 and $50 \%$. A marked reduction in perinatal mortality could be obtained by: (1) early referral for ante-natal care; (2) good control of maternal glycaemia, aided by serial blood glucose measurements; (3) timing of delivery on the basis of a positive 'shake test'. This simple programme of management can be applied even in cen- tres where facilities are limited and experience of the condition rare.

\section{References}

1. Kinnear TW, Ojo OA (1966) Pregnancy and diabetes in Nigeria. W Afr Med J 15: 146-148

2. Notelovitz M (1970) The pregnant Bantu diabetic. S Afr Med J 44: $1171-1175$

3. CampbellCD (1971) Frequency of diabetes with special respect to diet. In: Rodriguez RR, Vallance-OwenJ (eds) Diabetes: Proceedings of Seventh Congress of the International Diabetes Federation. International Congress Series No.231. Excerpta Medica, Amsterdam, pp 325-330

4. Sutton C (1977) Practical approach to the problems of the parturient diabetic in developing countries. Br Med J 2: 1069-1072

5. White $P$ (1971) Pregnancy and diabetes. In: Marble A, White $P$, Bradley RF, Krall LP (eds) Joslins's diabetes mellitus. Lea and Febiger, Philadelphia, pp 581-598

6. Diabetes mellitus (1965) Report of a WHO Expert Committee. WHO Technical Reports Series 310. WHO, Geneva

7. Clements JA, Platzker ACG, Tierney DF, Hobel CJ, Creasy RK, Thibeault DW, Oh W (1972) Assessment of the risk of respiratory distress syndrome by a rapid test for surfactant in amniotic fluid. N Engl J Med 286: 1077-1081

8. Wagstaff TI, Bromham DR (1973) A comparison between the lecithin sphingomyelin ratio and the 'shake test' for the estimation of surfactant in amniotic fluid. J Obstet Gynaecol Br Commonw 80:412-417

9. Dubowitz LMS, DubowitzV, GoldbergC (1970) Clinical assessment of gestational age in the newborn infant. J Paediatr 77 : $1-10$

10. Thompson AM, BillewiczWA, Hytten FE (1968) The assessment of fetal growth. J Obstet Gynaecol Br Commonw 75: 903-916

11. Pederson J, Mølsted-Pederson L, Andersen B (1974) Assessors of fetal perinatal mortality in diabetic pregnancy. Diabetes 23 : 302-305

12. Stowers JM, Sutherland HW (1975) The use of sulphonylureas, biguanides and insulin in pregnancy. In: Sutherland HW, Stowers JM (eds) Carbohydrate metabolism in pregnancy and the newborn. Churchill Livingstone, Edinburgh, pp 205-220

13. Robert MF, Neff RK, Hubbel JP, Taeusch HW, Avery ME (1976) Association between maternal diabetes and the repiratory distress syndrome in the newborn. N Engl J Med 294: $351-360$

14. Avery ME, Gatewood OB, Brumley G (1966) Transient tachypnoea of the newborn. Am J Dis Child 111:380-385

15. Brazy JE, Crenshaw MC, BrumleyGW (1978) Amniotic fluid cortisol in normal and diabetic pregnant women and its relation to respiratory disease in the neonate. Am J Obst Gynecol 132: $567-570$

16. Dalenburg GW, Martin FIR, Jeffrey PE, Horacek I (1977) Amniotic fluid lecithin/sphingomyelin ratio in pregnancy complicated by diabetes. Br J Obstet Gynaecol 84: 294-299

17. Fairbrother P, von Middelkoop A, Carson B (1979) A simple foam test on liquor amnii to predict neonatal outcome. Trop Doct $9: 81-94$

Received: 6 August 1980

and in revised form: 6 July 1981

Dr. R. B. Fraser

University Department of Obstetrics and Gynaecology

Clinical Sciences Centre

Northern General Hospital

Sheffield S5 7AU, UK 